\title{
Debate
}

\section{Scar revison is a useless operation}

\author{
Bimal Mody \\ Consultant Plastic Surgeon, P. D. Hinduja National Hospital, India.
}

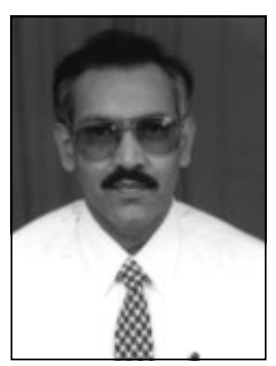

Address for correspondence: Dr. Bimal Mody, Consultant Plastic Surgeon, P. D. Hinduja National Hospital, Mumbai, India.

E-mail: bmody@vsnl.com

\section{INTRODUCTION}

he Webster's dictionary defines a scar as "a permanent mark on the skin or tissue consisting of fibrous tissue formed when a wound, ulcer heals." The World Book Encyclopedia defines a scar as "a permanent mark left after an injury on the skin or other parts of the body heals". The imperative word is permanent. I could end here. Permanent means permanent.

All wounds except those created and healed before the early third trimester of intra uterine life heal with scarring. (Mackool R J et al, Clinics in Plastic surgery July 1998).

In clinical practice as large number of patients come to us, plastic surgeons, with hope and scars expecting miracles; as much publicized by our own colleagues as by the media.

Undoubtedly, we wish to help these patients and we can do so if:

1. There is some distorting or misalignment associated with the scar.

2. There is hypertrophy, cause of which we can guess/ diagnose and nullify.

3. There is a tissue deficit, which we can replace.

4. The scar is not in RSTL.

But in those cases where none of the above is present, and there are a lot of cases like that, there is very little a scar revision does for the patient that he/she would be grateful for. For example scars on the forehead parallel to the RSTL, which are a little wide and shiny, revision rarely makes them much better at least as far as the patient is concerned. The shininess continues and the scar stretches again to some extent making the patient unhappy.

Another very bad scar to attempt revision is the one on the forearm after a radius plating. It looks stretched, shiny, and hairless and often has cross-hatchings.

\section{Dear Readers}

From this issue we are starting a new section entitled 'Debate'. This will deal with slightly controversial subjects, which can be argued for or against. The debate will not require detailed bibliography and references etc., but will still be scientific in its arguments. We hope it will remain lighthearted and add an element of spice and humour. Suggestions for future debate topics as well as nominations for proponents and opponents are welcome. Please give us your feedback about this new section.

Mukund Thatte 
Attempted revision does not change this to the patient's satisfaction. Often attempts at removing the cross-hatching may require a tissue expander or serial excisions. Silastic sheets and ointments don't do much good either. With time the scar fades but is still very obvious in thin, hairless dark forearms.

Scars on the back, parallel to the spine of the scapula, i.e. transversely across the shoulders, are deep wide and look very unsightly. Here too revision is rarely helpful. Despite all attempts to resuture the scar, incorporate a $\mathrm{Z}$, take non-absorbable sutures to splint the wound etc., the scar stretches, deepens and looks the same after 6 months, only now a little longer then before!

I think that scar revision is an operation where the satisfaction of performing the operation is entirely with the surgeon and patients are never satisfied. This may be because adult tissue always heals with fibrosis, and hair and other dermal elements do not regenerate, we know this but does this information make the patient happy?

It is human nature to be hopeful and a father with an unmarried 28 years old daughter at with a scar on her nose hopes that when he arrives to the office of a plastic surgeon, he will ultimately leave it with a perfect daughter without a scar on her nose and Hritik Roshan waiting out side to marry his daughter! Unfortunately this does not happen and even if India is shining.

Ultimately the test of any cosmetic surgery operation is the satisfaction it bestows to the patient and not what the surgeon believes. Cosmetic scar revision is by definition not a life saving or essential operation and is done so that we can make the patient happy. If in spite of explaining the likely result to the patient, he/she is dissatisfied, the failure is of the operation and I would stand by my statement that Scar revision is a useless operation. 